\title{
DERECHO DE LAS RELACIONES LABORALES EN EL SECTOR PÚBLICO Y LA CUARTA REGLA DEL PRINCIPIO PROTECTOR
}

LABOR RELATIONS LAW IN THE PUBLIC SECTOR AND THE FOURTH RULE OF THE PROTECTIVE PRINCIPLE

\section{Gonzalo Ubilla Fernández*}

Resumen: El presente trabajo se centra en desarrollar la cuestión de las relaciones laborales en el sector público, y más en concreto, en la esfera del carácter tuitivo que despliega el ordenamiento jurídico uruguayo sobre el vínculo funcional entre el Estado como empleador y el funcionario público como trabajador. El enfoque que se tomará sobre la temática planteada será desde la visión de los principios generales del Derecho del Trabajo, y la postura constructiva silogística con una mirada de tertium genus entre el Derecho del Trabajo y el Derecho Administrativo para el fenómeno de las relaciones laborales en el sector público. En base a esa idea de formación y construcción común entre ambas ramas del Derecho, se intentará plantear la figura de una cuarta regla en la forma de actuación del principio protector del Derecho del Trabajo. Se buscará definir cuáles serían los impactos y alcances de la presencia de este nuevo instituto jurídico con afán tuitivo de

\footnotetext{
* Doctorando Ph.D. (c) en Internacionalización de los Sistemas Jurídicos y Derechos Fundamentales por la Università degli Studi della Campania "Luigi Vanvitelli" (Caserta, Italia). Licenciado en Relaciones Internacionales por la Universidad de la República (Montevideo, Uruguay). Miembro e investigador de la Red Internacional de Cátedras, Instituciones y Personalidades sobre el Estudio de la Deuda Pública (RICDP). Investigador de "Espacio de trabajo", grupo de investigación sobre Derecho del Trabajo y de la Seguridad Social y las Relaciones Laborales, de la Universidad de la República (Montevideo, Uruguay), registrado en la Comisión Sectorial de Investigación Científica (CSIC). https://orcid.org/0000-0002-3744-0697. g.ubillafernandez@gmail.com
} 
los funcionarios públicos y aportando un nuevo elemento distintivo para seguir pensando si estamos ante una nueva rama jurídica autónoma o no.

Palabras clave: Derecho Administrativo, Derecho del Trabajo, relaciones laborales, sector público, Uruguay

Abstract: This paper focuses on developing the issue of labor relations in the public sector, and more specifically in the area of the protective nature that the Uruguayan legal system displays on the functional link between the State as employer and the public official as worker. The approach to be taken on the subject will be based on a vision of the general principles of Labor Law, and a constructive syllogistic position in a tertium genus view between Labor Law and Administrative Law for the phenomenon of labor relations in the public sector. On the basis of this idea of common formation and construction among both branches of Law, an attempt will be made to propose the figure of a fourth rule in the form of action of Labor Law operates. Analyzing the impact and scope of the presence of this new legal concept with the aim of protecting public officials and providing a new distinctive element to continue thinking about whether or not we are dealing with a new autonomous branch of Law.

Keywords: Administrative Law, Labor Law, Labor Relations, Public Sector, Uruguay

Sumario. I. Relaciones laborales en el sector público. I.1. Posiciones doctrinarias. I.2. Peculiaridades del Estado como empleador. I.3. Jurisprudencia. II. El principio protector y su cuarta regla. III. El precedente administrativo: valor jurídico y límites. IV. Conclusiones. Referencias.

\section{RELACIONES LABORALES EN EL SECTOR PÚBLICO}

La figura del Estado como entelequia y constructo del pacto social nos muestra esa imagen del leviatán hobbesiano (1997), con el territorio, la población y el poder etático (con su carácter de imperio). Asimismo, en forma más contemporánea se ha ido elaborando la idea del Estado como aparato, como institución-persona en la idea de Hauriou (1968), fundamento de la Administración. El Estado debe realizar toda una plétora de funciones, cometidos y servicios para sus ciudadanos o administrados, presentando un conjunto de órganos y sistemas orgánicos—tomando los aportes sobre la 
teoría del órgano de Méndez (1971) — que muestra cómo se configura la estructura, organización y diagrama del Estado.

Dentro de las distintas unidades de la estructura del Estado aparece la necesaria intervención humana, como ejecutora de la voluntad del órgano en virtud del interés general y público, ajustada a la imagen del cargo. Siendo así que la participación de los individuos en la administración se da en forma primordial en relación al cargo y al órgano, bajo la figura de un vínculo funcional. Se personifica así al funcionario público o también llamado servidor público que realiza su labor para con el Estado.

Resulta pertinente puntualizar que Uruguay cuenta con una definición legal, que la encontramos en la Ley 19.121, y que regula el Estatuto de los Funcionarios de la Administración Central, de "funcionario público" (que haremos extensiva a todo el Estado en sentido amplio). Conforme al Art. 3, es "funcionario público" todo aquel individuo que, incorporado mediante un procedimiento legal, ejerce funciones públicas en un organismo del Estado bajo una relación de subordinación y al servicio del interés general. Nótese que la doctrina y la jurisprudencia mayoritaria uruguaya, desde antes de la ley, ya tenían un concepto amplio de funcionario público ${ }^{1}$, siendo toda persona designada por autoridad competente que presta servicios a una entidad estatal (Correa Freitas y Vázquez, 2011, pp. 38-40).

\section{I.1. Posiciones doctrinarias}

Las principales posiciones han tratado de responder y abordar cuestiones sobre el fenómeno de los funcionarios públicos, su vínculo jurídico con el Estado y la naturaleza ontológica del mismo, así como tratar de desentrañar cuál es la rama del Derecho que corresponde para su regulación. Se suscitan así diversas teorías, que, como dijera Hernández Álvarez (1993) en referencia a la teoría del ejercicio de la función pública, se trata de "una zona fronteriza entre el Derecho Laboral y el Derecho Administrativo, cuyo análisis está lleno de dificultades" (p. 85).

\footnotetext{
${ }^{1}$ Resulta pertinente puntualizar que cuando se emplea la expresión "funcionario público" estamos haciendo referencia a los individuos que estarían comprendidos en el marco de la "función pública" y además son asimilados a la carrera administrativa. Entendiendo que los extra presupuestados o contratados, no ingresan a la carrera administrativa (son funcionarios a término), siendo que la ley los califica especialmente según su modelo de contrato y vínculo con el Estado (Delpiazzo, 1993, pp. 112-113). Se excede del presente trabajo el análisis de la gran cantidad de puntos de conexión que se materializan entre el Derecho Administrativo y el Derecho del Trabajo, y todas aquellas modalidades de contratación (no presupuestadas) que el Estado utiliza y que la nueva Ley 19.121 viene a ordenar y simplificar (Durán Penedo, 2012, p. 100).
} 
En primer lugar, se puede destacar la gran división del concepto, entre el contractualismo y el anticontractualismo, donde el eje de corte es contraponer el Derecho Público y el Derecho Privado. La visión contractualista asimila la relación jurídica entre el funcionario público y el Estado, bajo la figura de un contrato, mientras que a contrario sensu, el anticontractualismo se focaliza en que la incorporación del individuo al Estado, revistiendo la calidad de funcionario público, es por acto administrativo, y de carácter estatutario, objetivo, general e impersonal. Notándose así que la primer visión se basamenta sobre la autonomía de la voluntad de las partes con espíritu bilateral y la segunda es de origen constitucional, legal o reglamentario con impulso unilateral del Estado.

En un segundo escalón, centrando la discusión sobre qué rama es la idónea para regular el fenómeno estudiado, se encuentran tres grandes posiciones:

(i) Posición dualista, con una marcada preeminencia del Derecho Público sobre el Privado, según la cual todo lo atinente a los funcionarios públicos debe ser regulado en forma exclusiva por el Derecho Administrativo. En esta línea, Martins (1965) plantea en primer lugar que los funcionarios públicos son los "ejerzan una función pública en virtud de una relación funcional" (p. 52), pudiendo entender por relación funcional al vínculo jurídico especial que une al individuo en cuanto funcionario público, con la entidad estatal, por el cual el primero se obliga a realizar la función pública, en la forma y condiciones que el Estado establezca unilateralmente. En esta línea, Feola (2001), explicando esta doctrina tradicional, aporta el concepto de "función pública" como "aquella actividad jurídica y material, que compete realizar a los órganos estatales ejerciendo el poder etático soberano, con el objeto de lograr el fin del Estado, en formas y condiciones que se establezcan normativamente, en forma unilateral" (p. 180). El vocablo unilateralmente denota cómo el Estado reviste la potestad de incorporar el individuo a la función pública, así como también modificar en cualquier momento las condiciones del vínculo, es decir, cambiar el estatuto. Lo que se ajusta al análisis de Martins (1965) sobre los caracteres esenciales de la relación funcional, es decir: (a) tiene naturaleza estatutaria; (b) determina una situación jurídica objetiva, unilateral y general; (c) es personalísima; (d) es bilateral o sinalagmática, en tanto crea derechos y deberes para ambas partes; y (e) se trata de un vínculo de Derecho Público, fundado en que cumple un fin público sobre el que centra su objeto. Esta posición implica la distinción para con el Derecho Privado, y más en concreto, y en forma excluyente, con el Derecho del Trabajo, siendo que no podrá integrarse por norma análoga en caso de vacío o laguna normativa ( $\mathrm{p}$. 144). 
(ii) Posición unitaria, que se fundamenta sobre la idea de que no existen diferencias sustanciales entre la prestación de trabajo en el sector privado y en el sector público, por lo que corresponde una unidad en cuanto al marco normativo que regula ambos sectores, extendiendo el alcance del Derecho Laboral al sector público. Es apoyada por Plá Rodríguez (1986), Levrero y Sarthou (1977), y Barbagelata (1977). Este último comenta que:

«El desenlace natural de la evolución que se advierte en la doctrina y la legislación, será equiparar ambas situaciones abarcando a los funcionarios públicos dentro del derecho del trabajo y admitiendo, a lo sumo, que el funcionario público tenga un estatuto especial, como lo tienen distintos grupos de trabajadores» (Barbagelata, 1977, p. 18).

\section{Encontramos así que:}

«El trabajo puede ser encarado desde el punto de vista del hombre y desde el punto de vista de la sociedad. Con relación al hombre, el trabajo es una necesidad de expresión y una oportunidad que tiene para dar satisfacción a su poder creador. Subjetivamente, tiene que ver además, con su necesidad y su deseo de subsistir. Considerándolo desde este ángulo, el trabajo tiene un sentido humano que interesa al hombre y forma parte de su conducta. Pero el trabajo puede ser considerado objetivamente y en este sentido el trabajo interesa de un modo vital a la sociedad» (De Ferrari, 1968, pp. 382-383).

Esta posición se funda en el principio de igualdad ante la ley de la prestación de actividades tanto privadas como públicas, en consideración de que esas actividades no tienen diferencias notorias entre ellas. La figura estatutaria del funcionario público no es óbice per se de que el funcionario público sea comprendido en el marco regulatorio del Derecho del Trabajo, a razón de que hay otras categorías de trabajadores que tienen regulación diferencial como los rurales, marítimos, entre otros.

(iii) Posición mixta, que propone la construcción de un Derecho General del Trabajo aplicable indiscriminadamente tanto al sector público como al privado. Es decir, tendrá primacía sobre las ramas del Derecho por revestir rango constitucional. La tesis de Cassinelli Muñoz (1962) lo muestra bien:

«Las normas constitucionales, internacionales y legales que regulan el trabajo en general, como hecho, atendiendo a sus aspectos fisiológicos, psíquicos, económicos, sociales, prescindiendo del origen estatutario o contractual, y de la naturaleza de Derecho Público o de Derecho Privado, de la relación o servicio en que se encuentra el empleado u obrero. Este conjunto de normas constituye un verdadero Derecho General del Trabajo, que prima sobre el Derecho Privado del 
contrato de trabajo y sobre el Derecho Administrativo de la función pública» (p. 230).

En una línea similar, plantea Silva Cencio (1977):

«No podría hablarse de una aplicabilidad del Derecho del Trabajo a los funcionarios públicos, como tampoco podría hablarse de la aplicabilidad del Derecho Administrativo a los trabajadores privados, sino de la existencia de normas comunes o de normas especiales de idéntico contenido, de diferente valor formal, originales algunas del área del Derecho Público y otros del Derecho Privado y adoptadas por el constituyente, el legislador, el administrador o el juez, ante la similitud de la problemática que se da en algunos aspectos de la dinámica de la relación laboral, cualquiera sea el lugar donde ésta se realice y la naturaleza jurídica y el vínculo que une al trabajador con el dador de trabajo» (p. 50).

Tenemos autores que utilizan la denominación de "Derecho Administrativo Laboral" (Flores Depkevicius, 1998, p. 103), y siendo de recibo destacar el aporte del maestro Cajarville (2012, pp. 484-485), que plantea que la regulación común resulta específicamente de las disposiciones constitucionales contenidas entre los artículos 53 a 57, que manda la especial protección y garantías sobre los derechos de los trabajadores, sin generar un distinción sobre la naturaleza de la relación de subordinación o del empleador, por lo que no excluye al sector público. Lo que se puede leer con el aporte de Risso Ferrand (2006), "la protección del trabajo, correctamente delimitada no presenta problema alguno para coexistir y armonizarse con la base fundamental que surge del Art. 59 [de la Constitución]" (Risso Ferrand, 2006, p. 755). En este punto, resulta imperioso resaltar que el funcionario público, indistintamente de que la relación jurídica con el Estado sea de forma estatutaria, es un trabajador.

(iv) Por último, sobre esta variopinta gama de posiciones y teorías, nos gustaría resaltar la de Racciatti (2001), que señalaba que "existe un Derecho del Trabajo del sector público (aplicable no solamente a quienes trabajan para la administración pública sin incorporarse a ésta, sino también a los funcionarios que trabajan en situación de dependencia)" (p. 743). Ciertamente, la reforma del Estado-lo que el autor llamaba "racionalización o redimensionamiento de la Administración Pública" (Racciatti, 1995, p. 882) — ayuda a ilustrar esta imagen de precarización de los vínculos funcionariales, y que, como plantea Rivas (1989), lleva a generar una línea todavía más sinuosa entre ambas ramas del Derecho:

«La expansión del servicio público, el aumento de los empleados públicos, la pérdida gradual de ventajas en relación con los trabajadores del sector privado, el aumento de la inflación y las dificultades emanadas de las rigideces presupuestarias 
constituyeron factores que determinaron una mayor frecuencia de los conflictos» (p. 296).

Esto anterior, termina desembocando en dos manifestaciones lógicas, que planteaba Racciatti (2001):

«Una en el plano instrumental, que se advierte en el traslado de técnicas del derecho colectivo del trabajo, originariamente admitidas solamente en la relación privada y otra de carácter sustantivo, que consiste en la extensión de la aplicación de normas y principios del derecho común del trabajo» (p. 750).

Además, este autor expresa sobre la Ley 18.508 de Negociación Colectiva en el Sector Público, que:

«Establece un sistema de relaciones laborales en el sector público (Art. 1) que no es meramente una negociación colectiva. Es un instrumento de gobernanza de las relaciones laborales que no es solo una forma de determinar condiciones de empleo. Se enmarca en principios que gobiernan el sistema. Los principios cumplen una triple función: informadora o inspiradora, normativa e interpretativa» (Racciatti, 2009, pp. 827-828).

Como se mencionaba ut supra, el presente texto se alinea con la idea de una construcción y elaboración conjunta por ambas ramas hacia un Derecho de las Relaciones Laborales en el Sector Público. Además, expresiones legislativas tales como la ratificación de los Convenios Internacionales de Trabajo No. 151 y 154, la Ley 18.508 sobre Negociación Colectiva en el Sector Público, la Ley 19.121-que plantea que el funcionario es un trabajador subordinado además de plantear un desarrollo de los vínculos no funcionariales con la Administración-, y la presencia de los Decretos No. 401/008 y No. 354/010 — de los que se infiere en forma fehaciente el reconocimiento del derecho de huelga por parte de los funcionarios públicos - , es que entendemos la conjunción jurídica que se materializa sobre la figura del funcionario público y el reconocimiento particular de la triangularidad (sindicato, negociación colectiva y huelga) del Derecho Colectivo del Trabajo, y del despliegue de fuentes y principios generales del Derecho Individual del Trabajo.

La barrera que antaño separara a ambos planos entre sector público y privado, hoy en día se vuelve más sinuosa o permeable por la incorporación de los grandes institutos del Derecho Colectivo del Trabajo. La ya mencionada Ley 19.121 del Estatuto de los Funcionarios de la Administración Central, mostró todo un espacio para la negociación en su proceso de formación (ejercida desde la legitimidad dada por la Ley 18.508). Justamente Barbagelata era quien planteaba que la negociación de las 
normas laborales era un aspecto característico y particular de la disciplina laboral, lo que en cierta medida contraviene la tesis clásica de Sayagués Laso (2002) sobre la situación estatutaria, "de carácter objetivo y general, creada unilateralmente y por lo tanto modificable en todo momento" (Sayagués Laso, 2002, p. 261).

\section{I.2. Peculiaridades del Estado como empleador}

El Estado como empleador presenta numerosas peculiaridades si se lo compara con la figura clásica del empleador del sector privado. El caso uruguayo sobre las relaciones laborales y la negociación colectiva, destaca la figura del tripartismo, es decir, la participación del sector empleador, del Estado y de las organizaciones de trabajadores. Cuando hablamos del sector público, el Estado pasa de ser un tercero calificado a tener el rol de empleador con sendos intereses y potestades. Dentro de estas últimas, destaca la figura de que es el que dicta las normas jurídicas (función legislativa), es quien debe realizar el control de su cumplimiento (inspección en función administrativa) y deberá aplicarlas o acatarlas en virtud de su condición de empleador.

La orientación de la contratación, el desempeño e incluso el reconocimiento o no de ciertos aspectos referentes a la labor realizada por el funcionario debe estar guiada por el interés general, aunque ciertamente, impacta e incide la figura del interés público ${ }^{2}$. Este último, muestra la presencia de la política y la economía en la actuación del Estado y su vinculación con el cuerpo funcionarial. Aunque, es menester tomar en cuenta la presencia de limitaciones de rango constitucional y legal que constriñen el accionar del Estado y a su vez, regulan los distintos órganos estatales, especialmente la materia presupuestal (impactando en el salario, licencias, contrataciones, entre otros). Las potestades exorbitantes, extraordinarias o de imperio caracterizan al Estado, especialmente si son discrecionales, pero su alcance debe ser medido en forma precisa en base a las normas de rango legal y los principios generales (del Derecho, administrativos, y como veremos ut infra, laborales).

La estructura burocrática y jerárquica de la Administración ha sido vista como un esquema anquilosado y predefinido. Frente a esto debe recordarse lo planteado sobre la reforma del Estado, que se caracteriza por varios aspectos. Por un lado, tenemos un impulso privatizador, traspasando el Estado todo un conjunto de bienes y derechos de una empresa estatal,

\footnotetext{
${ }^{2}$ La expresión "interés público" referencia al interés del gobierno en el desarrollo de sus políticas y programas, y no a la observancia de todo el quantum de la sociedad en virtud del reconocimiento de derechos y satisfacción de las necesidades de la población.
} 
hacia la figura de una persona jurídica de Derecho Público no estatal, como sería el ejemplo de la Dirección Nacional de Impresiones y Publicaciones Oficiales (IMPO). También se ve un sistema de reconversión laboral tendiente a facilitar el pasaje de los "recursos humanos" del sector público al sector privado, como retiros incentivados, redistribución en otros organismos, reinserción laboral o empresarial en el sector privado, expansión de los vínculos no funcionariales, entre otros.

La reacción directa a todo este esquema de afectación a la realidad de las relaciones laborales en el sector público, deviene en fortificar la tutela de la función pública tratada como trabajo. Ampararse en la garantía constitucional que expresaba Cajarville (2012),

«queda totalmente configurada esa relación con todos sus caracteres: sujetofuncionario- que presta su actividad intelectual o corporal idéntica en sustancia a la de un trabajador privado; "relación de trabajo o servicio" de naturaleza pública o de Derecho Público, y sujeto empleador estatal» (p. 503).

\section{I.3. Jurisprudencia}

La casuística es variada y muestra diversas tendencias jurisprudenciales, si bien por un lado se reconoce la existencia de un bloque común de normas protectoras de los trabajadores independientemente que estos sean públicos o privados, el Tribunal de lo Contencioso Administrativo se ha concentrado en negar la tesis mixta de la existencia de una Teoría General del Derecho del Trabajo. Intentaremos ilustrar en forma sintética algunos pronunciamientos de nuestras autoridades jurisdiccionales.

Así llegamos a soluciones como la de la Sentencia No. 4-350 del 5 de junio de 2013, dictada por el Tribunal de Apelaciones en lo Civil de $5^{\circ}$ Turno, que expone: "Más allá de reconocer ciertos derechos a los trabajadores independientemente de que se desempeñen en el ámbito privado o en el público, la propia Constitución prevé que existan soluciones estatutarias aplicables a los funcionarios públicos [...]".

El Juzgado Letrado de Primera Instancia en lo Contencioso Administrativo de $2^{\circ}$ Turno, en la sentencia No. 110-29, del 11 de febrero de 2015, condena al Estado en su calidad de empleador, por configurarse acoso laboral contra una funcionaria, y expresa:

«Esta Sede en otros pronunciamientos previos ha sostenido que toda relación de trabajo sea ésta de carácter privado o público donde el empleador en este último caso es el Estado conlleva el cumplimiento de diversas obligaciones a cargo del empleador para la tutela de los derechos fundamentales del trabajador, entre ellas, la obligación de respetar la dignidad y honor del trabajador o funcionario. Dicha obligación emerge consagrada específicamente en el art. 54 de la Constitución». 
Incluso vemos fallos que incorporan soluciones ius laboralistas para casos con funcionarios públicos. El Tribunal de lo Contencioso Administrativo se pronunció en sentencia No. 233, del 23 de abril de 2013, por el que varios funcionarios públicos del Ministerio de Ganadería, Agricultura y Pesca (MGAP), accionan ante el Banco de Previsión Social frente a un acto administrativo que no les reconoce la antigüedad laboral previa a revestir el carácter de presupuestados. El Alto Tribunal dispuso que,

«se encuentra inequívocamente acreditado el vínculo de dependencia que unió a los actores con el MGAP desde el inicio de sus respectivas funciones. [...] una correcta aplicación de los principios de primacía de la realidad y de verdad material, lleva a descartar las formas utilizadas por el Ministerio para contratar inicialmente a los actores, en tanto surge de la realidad fáctica, suficientemente acreditada en autos, que el vínculo que ligó a los mismos desde un principio fue aquel perteneciente a una relación de subordinación, típica del contrato de trabajo"».

En línea similar vemos que el Tribunal de lo Contencioso Administrativo, en la sentencia No. 17, del 17 de febrero de 1975, insinúa en forma parca una orientación hacia el reconocimiento de algunos principios que caracterizan al Derecho del Trabajo, se recoge el principio protector al utilizar la expresión "la parte más débil" en referencia al funcionario público.

\section{EL PRINCIPIO PROTECTOR Y SU CUARTA REGLA}

Plá Rodríguez (1978), define a los principios como:

«Las líneas directrices que informan algunas normas e inspiran directa o indirectamente una serie de soluciones por lo que pueden servir para promover y encauzar a la aprobación de nuevas normas, orientar la interpretación de las existentes y resolver los casos no previstos» (p. 9).

Así como también se observa la visión de Dworkin (1998) sobre el tema:

«Llamo "principio" a un estándar que es respetado, no porque constituya un avance o el aseguramiento de una situación económica, política o social considerada conveniente, sino porque es un requerimiento de justicia o equidad o alguna otra dimensión de moralidad» (p. 22).

El principio protector se concibe como el criterio fundamental, rector y orientador del Derecho del Trabajo, ya que no solo se inspira en un propósito de igualdad, sino que tiene como objetivo el amparo preferente a 
una de las partes: el trabajador. Trasciende la paridad jurídica y la equiparación de las partes, y se concentra en proteger a una de las partes que en virtud de la relación jurídica es intrínsecamente débil, materializando así una igualdad sustantiva y real.

La igualdad ante la ley es cuestionada y confrontada con la realidad palpable, por lo que solo mediante la protección y tutela de la parte de más débil se consigue equilibrar el desequilibrio, y alcanzar una noción de equidad. Como planteara Couture (1941), "el procedimiento lógico de corregir las desigualdades es el de crear otras desigualdades" (Couture, 1941, p. 115). Añade Radbruch (1951) que:

«La idea central en que el Derecho social se inspira no es la idea de igualdad entre las personas, sino de la nivelación de las desigualdades que entre ellas existen. La igualdad deja de ser así punto de partida del Derecho, para convertirse en meta o aspiración del orden jurídico» (p. 162).

El principio protector se limita a establecer una interpretación coherente con la ratio legis. Pensando en la idea de la mens legis que planteara Barassi (1953, p. 245), la intención del legislador es el establecimiento de un sistema de protección del trabajador. Es así que el aplicador del Derecho, como intérprete, deberá cumplir con ese propósito. Corresponde puntualizar que no se trata de un método especial de interpretación, sino de un principio general que inspira todas las normas del Derecho del Trabajo y que debe ser tenido en cuenta en su aplicación, por lo que este principio preside la interpretación en la actuación de cada una de las fuentes, centrándose en arrojar luz al resolver conflictos jurídicos.

Además, cabe destacar, como plantea Plá Rodríguez (1978) en coincidencia con Kaskel-Dersch y Gianotti, que "no es necesaria esa consagración (consagración del principio en el Derecho positivo), la propia naturaleza del principio lo sitúa por encima del Derecho positivo" (p. 88). Considerando que en nuestro Derecho, el Art. 53 de nuestra Lex Magna ${ }^{3}$ habla de "protección especial" del trabajo, deja patentizado que el principio protector tiene una clara base constitucional.

${ }^{3}$ El artículo 53 de la Constitución de la República Oriental del Uruguay, dispone que:

«El trabajo está bajo la protección especial de la ley. Todo habitante de la República, sin perjuicio de su libertad, tiene el deber de aplicar sus energías intelectuales o corporales en forma que redunde en beneficio de la colectividad, la que procurará ofrecer, con preferencia a los ciudadanos, la posibilidad de ganar su sustento mediante el desarrollo de una actividad económica». 
Este principio cuenta con las formas de aplicación o reglas mediante las cuales se materializa o expresa el principio protector. Las tres reglas en forma somera son:

(i) Regla in dubio pro operario, criterio que debe utilizar el juez o el aplicador del Derecho al interpretar la norma. En caso de haber varios sentidos posibles, elegirá la que sea más favorable para el trabajador.

(ii) Regla de la norma más favorable. La situación suscitada se da al haber más de una norma aplicable, y se deberá optar por aquella que sea más favorable para el trabajador. Esta operación se hará, aunque la misma no hubiese correspondido según los criterios clásicos sobre jerarquía de las normas.

(iii) Regla de la condición más beneficiosa. La aplicación de una nueva norma nunca debe servir para afectar o ir en detrimento de las condiciones más favorables en que pudiera hallarse un trabajador.

En este punto, corresponde recordar lo expresado anteriormente sobre las potestades extraordinarias, realizadas en forma unilateral y muchas veces con amplio margen discrecional que ejercita el Estado. Estas potestades se vuelven tangibles en diversos aspectos, tales como una expropiación, la imposición de un tributo, entre otros. Considerando, la temática sobre la que se viene desarrollando, nos importan estas potestades en el vínculo funcional, las que ejercería el Estado como empleador sobre los funcionarios públicos, ejemplificando un notorio desequilibrio y una marcada sujeción por parte de los funcionarios, en tanto el Estado puede modificar las condiciones (estatuto) en cualquier momento. En este sentido, lo expresado por Staricco y Guevara (2001) coincide con la visión antes mencionada sobre el tema, ya que "los principios laborales deben inspirar la solución de los problemas generados en la relación de trabajo dependiente, sea de la actividad pública o privada" (p. 221).

Consecuentemente, cuando se habla más arriba sobre los principios, surgieron máximas del Derecho como la justicia, la equidad y la paridad, por lo que entendemos que el principio protector acude frente a este desequilibrio y se expresa mediante una cuarta regla o forma de aplicación: el precedente administrativo.

\section{EL PRECEDENTE ADMINISTRATIVO: VALOR JURÍDICO Y LÍMITES}

El precedente administrativo ha sido abordado por los juristas cuestionando en gran medida su valor jurídico. En este sentido, Rotondo (2010) plantea que: 
«El precedente administrativo es una "conducta previa" de la Administración que contiene un acto anterior que resuelve un caso similar a otro, actual, por lo cual aquel tiene efectos hacia el futuro, momento en que se dirá que se actúa "como se hizo antes" o incluso "como se ha hecho siempre"» (p. 646).

Cabe distinguir que el precedente administrativo, a la hora de calificarlo y determinar su naturaleza jurídica, no es costumbre y no parte de base consuetudinaria alguna, debido a la ausencia del elemento psicológico, y si bien numerosos autores lo han englobado en el concepto de prácticas administrativas, sin embargo tomando en cuenta su impacto sobre el proceder de la Administración, se entiende que tienen asidero propio. Robaina (2011) invoca el "paradigma de la Administración previsible y confiable" (p. 158), alineado con principios estructurales como la igualdad, la seguridad jurídica y la confianza legítima. Siguiendo esto último, Soto Kloss (1999) señala que:

«La actuación de toda organización requiere de uniformidad en su forma de desarrollarse, uniformidad en sus decisiones, y uniformidad, por lo tanto, de sus modos o formas de actuación, requiere de una ordenación que regule de manera estable y permanente su actividad, lo que originará lo que puede llamarse la "procedimentalización" del actuar administrativo, carácter que dará regularidad, homogeneidad, permanencia y previsibilidad de toda la actividad de que se trata; y es que esta estabilidad, homogeneidad y previsibilidad posibilitan verdaderamente la eficacia y eficiencia de tal actual. Ante iguales situaciones y circunstancias se adoptan iguales decisiones» (p. 401).

Además, desde el principio de legalidad vemos planteamientos como:

«El sometimiento del Estado al Derecho no implica, en efecto, sólo la subordinación a la ley formal, como podría hacer pensar la locución legalidad, sino a todo el orden jurídico, desde los principios generales del Derecho hasta los precedentes en cuyo seguimiento esté comprometida la garantía de igualdad [...]» (Comadira, 2003, p. 6).

Podemos contemplar varios puntos, pero en general los requisitos para configurar el precedente administrativo son:

(i) Objeto idéntico o lógicamente análogo: el acto que se emite debe versar sobre una situación sumamente similar en sus características y alcance a una ya resuelta previamente.

(ii) Mismo sujeto emisor: el ente u órgano público que pronuncia ese dictamen o acto administrativo deberá ser el mismo que dictará el acto anterior en una situación similar, sobre el que se basa el precedente. 
(iii) Juridicidad: toda la situación debe ser jurídicamente relevante, así como también el acto anterior sobre el que se plantea el precedente debe haber sido emitido conforme a Derecho (no adolecer por méritos ni ilegitimidad).

Despliega así sus efectos el precedente administrativo, en virtud de proveer una confianza legítima al administrado, de garantizar la igualdad entre sujetos, y especialmente de inhibir la arbitrariedad de la Administración. Este último punto resulta especialmente interesante, ya que tener mecanismos para controlar las potestades exorbitantes del Estado cuando estas se dan en un marco discrecional, es garantía de una buena Administración, evita la desviación de poder, protege el interés general y aporta seguridad y certeza. Como plantea Ortíz Díaz (1957), "el principio general del derecho de la igualdad que se proyecta en diversas facetas y disciplinas, comprende la igualdad de los ciudadanos ante la Administración, aun cuando esta actúe en el ejercicio de sus competencias discrecionales" (pp. 95-97).

Sobre la cuestión del valor jurídico numerosos planteamientos han sido encontrados. Durán Martínez (2010) se adhiere a que se trata de una fuente formal del Derecho, mientras que Rotondo (2010) sostiene que no es fuente formal, pero tiene una visible repercusión o relevancia jurídica el precedente administrativo. Siendo también de recibo puntualizar que tenemos autores como Díez Sastre (2008), que sostienen que la fuente determinante de los precedentes es la ley, los mismos no tienen un valor jurídico autónomo, estando arraigados a la normal legal para concebir poder vinculante (posición excluyente). García de Enterría y Fernández (1998), por su parte, comentan:

«El precedente administrativo reiterado puede tener un cierto valor vinculante para la propia Administración, en el sentido de que apartarse de él en un caso concreto puede ser índice de un trato discriminatorio, de una falta de buena fe, de una actitud arbitraria. Este juicio se explica fácilmente, sin necesidad de acudir a la tesis del precedente como costumbre [...]» (p. 67).

El autor español apoya la idea de que el precedente administrativo no es de raigambre consuetudinaria, no es fuente formal tampoco, pero sí reviste cierto valor, una cuestión relevante en virtud del accionar reiterado de la Administración.

No es menor, por último, señalar que existen ciertos límites al ejercicio del precedente administrativo. Este instituto jurídico no opera como un yugo a los solos efectos de constreñir el accionar de la Administración, sino que se pueden dar diversos escenarios. Primeramente, es necesario cumplir con los requisitos ya expuestos anteriormente. Por otro lado, pensemos que el 
precedente cumple la función de arrojar luz o transparencia sobre las áreas más grises del accionar del Estado (la discrecionalidad), por lo que el apartamiento del precedente es posible, aunque deberá ser fundamentado y justificado en forma clara y precisa.

La posibilidad de apartarse del precedente lleva como corolario demostrar (obligación probatoria) que no se está actuando con arbitrariedad, y podrá darse en los siguientes supuestos: (a) por razones de interés público; o (b) por revestir ilegitimidad el acto o actuación anterior.

Así, el autor Díez Picazo (1982), plantea que "cuando la Administración se aparta de estos principios, tiene la carga de probar que existe un interés público que así lo justifica. En otras palabras, el interés público contrario a los principios generales del Derecho no se presume" (p. 23).

Siendo así que Robaina (2011) plantea la cuestión del dinamismo de la noción de interés público, tomando en consideración el impacto de circunstancias históricas y hasta ideológicas para su definición en cierto momento y contexto, que puede devenir en generar un arbitrio antojadizo de la Administración. Por tratarse de un concepto jurídico indeterminado, deberá por ende ser analizado por las autoridades jurisdiccionales cuando se presente una adecuada, suficiente y razonable fundamentación de cómo esa actuación impacta sobre el interés general, sin perder de vista los derechos particulares afectados por la inobservancia del precedente.

Tomando en cuenta la diatriba entre si el precedente administrativo es o no fuente formal, y con especial consideración de lo expresado anteriormente, se sostiene que se trata de la expresión o forma de aplicación de principios generales del Derecho. Es una expresión que impacta en el principio de igualdad que tiene el contribuyente frente al Fisco recaudador en el Derecho Tributario. Se observa también en el Derecho Administrativo, en la figura del administrado y su derecho a ser tratado de forma igualitaria. En este caso concreto, se trata de la cuarta regla del principio protector en el marco del Derecho de las Relaciones Laborales en el Sector Público.

\section{CONCLUSIONES}

En conclusión, este nuevo instituto jurídico aporta tres puntos esenciales: primero, un mayor alcance tuitivo de un principio rector; segundo, ejemplifica el concepto y la noción de que el Derecho es un todo, y que sus ramas no son compartimentos estancos, por lo que pueden retroalimentarse y construirse desde unas y otras; y, finalmente, esta propuesta abre la puerta a seguir pensando sobre la figura de una nueva rama 
del Derecho. Estos aportes se entrelazan exponiendo un escenario más favorable para los funcionarios públicos, a saber:

1. Entender que el precedente administrativo aplica como una regla dentro del principio protector, y muestra un panorama más garantista y menor desequilibrio entre el funcionario público como trabajador y el Estado como empleador. Amplía el alcance del principio y facilita su operacionalización sobre las realidades fácticas que se materializan cotidianamente en el plano del proceder de la Administración respecto de sus empleados.

2. Se generan dos perspectivas tuitivas tanto del trabajador como del administrado, por un lado, una configuración particular del principio protector para el sector público atendiendo a sus matices tal como expresara el Art. 59 de la Constitución ${ }^{4}$, y no contraviniendo la imagen estatutaria. Por otro lado, el precedente en línea con el favor debilis, permitirá incoar ante una Administración que no justifique su apartamiento de una línea de actuación clara, habilitándose el poder exigir una congruencia razonable y lógica en el tratamiento de los distintos funcionarios.

3. Se aúnan fuerzas y se construye en forma común entre ambas ramas del Derecho, ya que el principio protector proviene de la línea laboralista y el precedente de la línea administrativista, generándose un elemento distintivo del "Derecho de las relaciones laborales en el sector público". Este elemento nos encamina a reflexionar en el futuro si nos encontramos ante una rama autónoma del Derecho o ante un Derecho especial no autónomo.

\footnotetext{
${ }^{4}$ El artículo 59 (acápite) de la Constitución de la República Oriental del Uruguay, dice así: "La ley establecerá el Estatuto del Funcionario sobre la base fundamental de que el funcionario existe para la función y no la función para el funcionario [...]”.
} 


\section{REFERENCIAS}

Barassi, L. (1953). Tratado de Derecho del Trabajo. Alfa.

Barbagelata, H. H., y Silva Cencio, J. (1977). Enfoque doctrinario sobre la aplicación del Derecho del Trabajo a los funcionarios públicos: mesa redonda. En Revista de Derecho Laboral (Ed.), Cursillo sobre Derecho del Trabajo y los funcionarios públicos (11-51). Biblioteca de Derecho Laboral, No. 5.

Barbagelata, H. H. (2009). El particularismo del Derecho del Trabajo y los Derechos Humanos Laborales. Fundación de Cultura Universitaria.

Cajarville, J. P. (2012). Sobre Derecho Administrativo (II). Fundación de Cultura Universitaria.

Cassinelli Muñoz, H. (1962). Régimen jurídico general de los trabajadores y estatuto de los funcionarios. Revista Derecho, Jurisprudencia y Administración, 58 (10), 230-234.

Comadira, J. R. (2003). La responsabilidad del Estado por su actividad lícita o legítima: principio de juridicidad y responsabilidad del Estado. Revista de Derecho de la Universidad de Montevideo, 2 (3), 5-21.

Correa Freitas, R. (2006). Trabajadores del Estado y Derecho Laboral. Revista Jurídica. La Justicia Uruguay, 133, 97-104.

Correa Freitas, R., y Vázquez, C. (2011). Manual de Derecho de la Función Pública. Fundación de Cultura Universitaria.

Costas, C., y Larrañaga, M. V. (2015). El funcionario público como trabajador del Estado: análisis jurisprudencial. Revista Derecho del Trabajo, 7, 117-130.

Couture, E. J. (1941). Algunas nociones fundamentales del Derecho Procesal del Trabajo. En Instituto del Derecho del Trabajo de la Facultad de Ciencias Jurídicas y Sociales (Ed.), Tribunales del Trabajo, Derecho Procesal del Trabajo (112126). Universidad del Litoral.

De Ferrari, F. (1968). Derecho del Trabajo (I). Depalma.

De la Cueva, M. (1973). El contrato colectivo en la nueva Ley Federal de Trabajo en México. En Facultad de Derecho y Ciencias Sociales de la Universidad de la República (Ed.), Estudios sobre la negociación colectiva en memoria de Francisco de Ferrari (401-424). Universidad de la República.

Delgado Soares Netto, F. (2017). Peculiaridades de las relaciones laborales en el sector público. En Asociación Uruguaya de Derecho del Trabajo y de la Seguridad Social (Ed.), Estudios de Derecho Laboral en homenaje al profesor Octavio Racciatti (89-96). Fundación de Cultura Universitaria.

Delpiazzo, C. (1993) Manual de contratación administrativa. Parte especial (II). Secretaría de la Presidencia, PRONADE.

Díez Picazo, L. M. (1982). La doctrina del precedente administrativo. Revista de Administración Pública, 98, 7-46. 
Díez Sastre, S. (2008). El precedente administrativo. Fundamentos y eficacia vinculante. Marcial Pons.

Durán Penedo, B. (2012). Funcionarios públicos. Modalidades de vinculación con el Estado (Administración Central). En Hugo Barreto Ghione (Coord.), La reglamentación del trabajo en los Consejos de Salarios y convenios colectivos: estudio de 13 sectores (99-118). UDELAR, CSEP, Fundación de Cultura Universitaria.

Durán Martínez, A. (2010). El precedente administrativo. Revista de Derecho de la Universidad Católica del Uruguay, 5, 51-78.

Dworkin, R. (1998). Los derechos en serio. Ariel.

Feola, M. C. (2001). Reflexiones sobre el Derecho del Trabajo y las relaciones laborales en el sector público. En Jornadas Uruguayas de Derecho del Trabajo y de la Seguridad Social AUDTSS (Ed.), XIII Jornadas Uruguayas de Derecho del Trabajo y de la Seguridad Social (177-201). Fundación de Cultura Universitaria.

Flores Dapkevicius, R. (1998). Algunas consideraciones generales acerca del TOFUP y del Derecho Administrativo Laboral. Revista de Derecho Público, 7 (14), 103124.

García de Enterría, E., y Fernández, T. R. (1998). Curso de Derecho Administrativo (I). Civitas.

Garmendia, M., y Vázquez, R. (2015). Incidencia del Derecho Laboral en el Estatuto del Funcionario Público de la Administración Central. Revista Derecho del Trabajo, 6, 77-92.

Hauriou, M. (1968). La teoría de la institución y de la fundación: ensayo de vitalismo social. Abeledo-Perrot.

Hernández Álvarez, O. (1993). La negociación colectiva de los empleados públicos: tránsito de la concepción estatutaria a la concepción laboralista. En Óscar Ermida y Antonio Ojeda (Eds.), La negociación colectiva en América Latina (85-95). Trotta.

Hobbes, T. (1997). El Leviatán. Atalaya.

Levrero Bocage, C., y Sarthou, H. (1977). Problemas que plantea la aplicación del Derecho del Trabajo a los funcionarios públicos: mesa redonda. En Revista de Derecho Laboral (Ed.), Cursillo sobre Derecho del Trabajo y los funcionarios públicos (54-87). Biblioteca de Derecho Laboral, No. 5.

Martins, D. H. (1965). Estatuto del funcionario. Facultad de Derecho y Ciencias Sociales de la Universidad de la República.

Méndez, A. (1971). La teoría del órgano. Amalio M. Fernández.

Ortíz Díaz, J. (1957). El precedente administrativo. Revista de Administración Pública, 24, 75-116.

Plá Rodríguez, A. (1978). Los principios generales del Derecho del Trabajo. Depalma. 
Derecho de las relaciones laborales en el sector público y la cuarta regla del principio...

Plá Rodríguez, A. (1986). El trabajador público y los convenios colectivos. Revista Derecho Laboral, 24 (143), 413-433.

Radbruch, G. (1951). Introducción a la filosofía del Derecho. Fundación de Cultura Universitaria.

Racciatti, O. (1995). La reestructuración de la función pública en la Ley 16.736. Revista Derecho Laboral, 38 (180), 871-899.

Racciatti, O. (2001). El Derecho del Trabajo en el sector público. Revista Derecho Laboral, 44 (204), 729-807.

Racciatti, O. (2009). Apuntes sobre la Ley 18.508 de negociación colectiva en el sector público. Revista Derecho Laboral, 52 (236), 821-838.

República Oriental del Uruguay (1967). Constitución de la República. Dirección Nacional de Impresiones y Publicaciones Oficiales, 2 de febrero de 1967.

República Oriental del Uruguay (1975). Sentencia No. 17 del Tribunal de lo Contencioso Administrativo, de 17 de febrero de 1975.

República Oriental del Uruguay (2013). Ley 19.121, Regulación del Estatuto del Funcionario Público de la Administración Central, 28 de julio de 2013.

República Oriental del Uruguay (2013). Sentencia No. 223 del Tribunal de lo Contencioso Administrativo, de 23 de abril de 2013.

República Oriental del Uruguay (2013). Sentencia No. 4-350 del Tribunal de Apelaciones en lo Civil de $5^{\circ}$ Turno, de 5 de junio de 2013.

República Oriental del Uruguay (2015). Sentencia No. 110-29 del Juzgado Letrado de Primera Instancia en lo Contencioso Administrativo de $2^{\circ}$ Turno, de 11 de febrero de 2015.

Rinaldi, R. (2005). Derecho del Trabajo y función pública. Revista del CIEJ. Espacio Abierto, 2, 44-64.

Risso Ferrand, M. (2006). Derecho Constitucional (I). Fundación de Cultura Universitaria.

Rivas, D. (1989). Las relaciones de trabajo en el sector público y el Convenio № 151. Revista Derecho Laboral, 32 (154), 295-375.

Robaina, I. (2011). Sobre el valor jurídico del precedente administrativo. Revista de Derecho y Tribunales, 17, 151-162.

Rotondo, F. (2010). Conducta previa de la Administración: ¿existe el precedente administrativo? La Ley Uruguay, 5, 644-652.

Sayagués Laso, E. (2002). Tratado de Derecho Administrativo (I). Fundación de Cultura Universitaria.

Soto Kloss, E. (1999). Acerca de la obligatoriedad de los precedentes en la actividad administrativa del Estado. Revista Chilena de Derecho, 26 (2), 399-403.

Staricco, J., y Guevara, E. (2001). Los principios del Derecho Laboral y su aplicación con respecto al funcionario público. En Jornadas Uruguayas de Derecho del 
Trabajo y de la Seguridad Social AUDTSS (Ed.), XIII Jornadas Uruguayas de Derecho del Trabajo y de la Seguridad Social (217-222), Fundación de Cultura Universitaria. 